\title{
No Moral Progress without an Objective Moral Ontology
}

\author{
Jaron Daniel Schoone \\ Berlage Lyceum, University of Amsterdam, Amsterdam, the Netherlands
}

Copyright $(\mathrm{C} 2018$ by authors, all rights reserved. Authors agree that this article remains permanently open access under the terms of the Creative Commons Attribution License 4.0 International License

\begin{abstract}
One of the definitions of philosophy is: the study of presuppositions. While many philosophers and scholars agree that human history exhibits moral progress, there seems to be confusion about the presupposed moral ontology that such a view entails. Moral ontology is the sub discipline of ethics which concerns questions such as whether moral facts exist objectively, where 'objective' means that such facts would exist independently from anyone's personal beliefs (mind-independent), or subjectively, where 'subjective' means that such facts depend on the beliefs and/or desires of persons (mind-dependent). This paper concludes that moral progress requires an objective moral ontology. Consecutively, this paper will raise considerable doubts concerning the idea that the objective ontological foundation of moral progress can be natural. On a natural ontological foundation (such as provided by evolutionary ethics) either moral progress appears to be non-objective or it seems to be altogether illusory.
\end{abstract}

Keywords Objectivity, Progress, Ontology, Non-naturalism, Meta-ethics

\section{Introduction}

In a survey titled "What Do Philosophers Believe?", targeting professional philosophers at 99 different institutions, over half of the respondents $(56,8 \%)$ claimed that their meta-ethical view is consistent with moral realism. Around a quarter of the respondents $(27,7 \%)$ hold an anti-realist view of morality [1]. For the sake of this paper I will assume that moral realism is true and will argue based on this assumption that one requires an objective moral ontology if one wishes to account for the existence of objective moral progress. Of course one could simply deny that moral realism is true, which according to the aforementioned survey about a quarter of the contemporary philosophers would do. I will discuss some of the consequences of moral anti-realism in my concluding remarks.

In the past decades, there have been many attempts to provide an ontological foundation for moral realism, with evolutionary explanations for morality becoming somewhat of a status quo. However, I would argue that such evolutionary explanations and other naturalistic foundations fail to ontologically ground morality. This becomes evident when examining the idea of moral progress. At a recent conference at the VU University in the Netherlands titled "Moral Progress: Concept, Measurement and Application" I defended the following deductive argument:

$\mathrm{P} 1$ : If there is objective moral progress, then an objective moral standard exists.

P2: If an objective moral standard exists, then it is either natural or non-natural.

P3: Nothing natural can function as an objective moral standard.

$\mathrm{C} 1$ : If there is objective moral progress, then a non-natural objective moral standard exists.

P4: There is objective moral progress.

C2: A non-natural objective moral standard exists.

The argument consists of four premises and two conclusions. Furthermore, the argument is deductive which means that if the premises are more likely to be true than false, then the conclusions follow necessarily and inescapably from the premises. The final conclusion $\mathrm{C} 2$ entails the existence of non-natural objects, which means that metaphysical naturalism is false. The argument as a whole is especially problematic for those moral realists who affirm naturalism. In the following sections I will discuss each of the premises and will conclude with some remarks on the implications of the conclusion.

\section{P1: If There Is Objective Moral Progress, Then an Objective Moral Standard Exists}

Before examining several examples that underscore this premise I will briefly explain the terms objective and moral 
progress. With objective I mean that moral facts are mind-independent. The truth or falsity of moral facts is independent of people's opinions on these facts. In the words of J.L. Mackie a moral objectivist is someone who thinks that morality is "part of the fabric of this world" [2]. It is important to distinguish this ontological claim from epistemic claims concerning morality. The argument that I am propounding is solely concerned with ontological objectivity. Just like there is something that makes it the case that "the cat is on the mat" or that " $7+5=12$ ", there is also something that makes it the case that "slavery is wrong". The question then becomes what this something is. However, it seems to me that this something being mind-independent and thus objective is one of the core concepts of a moral realist position.

The term moral progress also requires a clear definition. I feel most comfortable with the definition of moral progress as given by Dale Jamieson, namely that "moral progress occurs when a subsequent state of affairs is better than a preceding one, or when right acts become increasingly prevalent." [3] Jamieson coined this "Naive Conception" of morality. His conclusion after careful consideration is that "in the end ... the Naive Conception can provide a notion of moral progress consistent with most normative views in moral philosophy." The naïve conception also seems intuitively correct. With progress we mean some form of positive change over time (regress being negative change over time) and in the case of moral progress the positive aspect concerns the change of moving closer to the morally good, whereas moral regress means that one moves closer to the bad or evil.

With these definitions in hand it seems clear that there has to be some kind of moral standard which is used to measure whether a person or society is changing progressively or regressively. If moral progress is objective, then this moral standard also has to be objective. I want to reiterate that I am primarily concerned with the ontological status of such a moral standard. To use an analogy: just like the meter is ontologically grounded in a piece of platinum, so too right and wrong have to be ontologically grounded in something. When one progresses from holding one moral proposition to another moral proposition, the latter being closer to the moral standard, one can speak of moral progress. In the case of moral progress ethicists often use the example of the abolishment of slavery. If the abolishment of slavery (particularly the North-American slave trade) is considered to be an example of objective moral progress, then one can ask the question what grounds this as being moral progress. For there have certainly been those who have claimed that in fact the abolishment of slavery was itself morally wrong or a sign of moral regress. If one wishes to hold the view that the abolishment of slavery is objective moral progress then it seems to me that one has to hold that slavery is wrong and that there is some kind of mind-independent fact about the world that makes it the case that slavery is wrong. Therefore, there has to exist some 'thing' in the world, which makes it the case that abolishing slavery is moral progress and not moral regress. This is what I take to be an objective moral standard.

Another example stressing the objectivity of moral progress concerns the following hypothetical situation. Suppose that the Nazi's would not have been defeated and would have succeeded in conquering the world and would have proceeded to either exterminate or brainwash every single individual who would disagree with their ideology. In this world there would be no one holding the belief that the Holocaust was wrong. But does this fact mean that the Holocaust wasn't wrong (or that the Holocaust was right)? The person who holds that it is still possible that the Holocaust was wrong even in a world where no single person holds this particular belief seems to be committed to a form of moral realism that includes objective moral facts.

Therefore the conclusion that there has to be an objective moral standard is reasonable when one already holds to the existence of objective moral progress. Notice that premise P1 presupposes moral objectivism. A moral non-objectivist, which I will refer to as a moral subjectivist, would simply deny the existence of any kind of objective moral facts, including those concerning moral progress. I will deal with the subjectivist position when discussing the fourth premise "There is objective moral progress".

\section{P2: If an Objective Moral Standard Exists, Then It Is either Natural or Non-natural}

Although P2 seems to be self-explanatory I will take this opportunity to define natural and non-natural, for these terms are used in a wide variety of ways. Some hold for instance that morality being natural means that morality is reducible whereas non-naturalism holds that moral facts are just brute facts about the world [4]. Others hold that natural means that moral facts are a posteriori and synthetic statements, whereas non-natural is taken to mean that moral statements are either a priori synthetic or analytic [5]. The way I will define natural comes closer to Moore's definition of natural when he writes: "by nature then I do mean and have meant that which is the subject matter of the natural sciences, and also of psychology" [6]. In other words, naturalism must be understood as metaphysical naturalism, the view that everything is reducible to natural or material objects. On naturalism, therefore, any objective moral standard has to be reducible to some natural entity or entities. This view is propounded more recently by a group of meta-ethicists known as the Cornell realists. Alexander Miller notes that "the Cornell Realists argue that we can view moral properties and facts as part of the natural fabric of the world for the same reason that we can view, for example, physical, chemical or biological facts as part of the fabric of the natural world, namely, that they pull their weight in explanatory theories." [7] The normative ethical theories that eventually ground morality in evolutionary or 
other biological facts can also be considered natural in this sense.

Non-naturalism then becomes the denial of metaphysical naturalism. It is not the case that everything is reducible to natural objects but there are non-natural objects and morality is grounded in these latter objects. Examples of non-natural views are for instance Platonism and Divine Command Theory, but the aforementioned view that moral facts are brute non-natural facts also fall within this category. With these clarifications in place P2 becomes self-evident, for P2 simply states that either metaphysical naturalism is the case or it isn't. Therefore the objective moral standard is either natural or non-natural.

\section{P3: Nothing Natural Can Function as an Objective Moral Standard}

This premise is a controversial one. I will attempt to show that this premise is likely to be true by discussing three difficulties with ascribing objective morality to natural objects, namely the location problem, the problem of speciesism, and the problem of evolutionary explanations for morality.

\section{The Location Problem}

If naturalism is true then at the fundamental level all objects in this world are reducible to their natural constituents, namely the elementary particles and forces described by the standard model of physics. Because the metaphysical naturalist holds that moral facts and properties are part of the natural world (either by being identical to something natural or by supervening on something natural) they must also hold that either elementary particles themselves or collections of elementary particles contain that which grounds morality. This is what gives rise to what Frank Jackson has labelled the "location problem" [8]. Moral facts and properties need to be given "a place in the scientific account of our world". But where can morality be placed or located within the realm of natural entities? No one would ascribe moral properties to elementary particles. But somehow there are collections of elementary particles that do exhibit moral properties. Since there are other collections of elementary particles that do not exhibit such properties it seems that the naturalist is required to explain why certain collections of particles have this moral dimension while others do not.

In a sense this problem is analogous to the problem of locating thoughts and other mental properties in the physical brain (the problem of consciousness). A naturalist will argue that the identity thesis is true, namely that mental states are identical to brain states. But it seems to be insufficient to simply state that this is the case. The naturalist will have to explain how it is possible that brain states and mental states are connected in the way that the naturalist is describing. And this appears very difficult to explain. In the words of John Searle: "...we really do not understand how brain processes cause consciousness." Interestingly Searle himself does believe that the conclusion that brain processes cause consciousness is warranted even without an explanation on how this is possible. He writes:

"The property dualist and I are in agreement that consciousness is ontologically irreducible. The key points of disagreement are that I insist that from everything we know about the brain, consciousness is causally reducible to brain processes; and for that reason I deny that the ontological irreducibility of consciousness implies that consciousness is something 'over and above', something distinct from, its neurobiological base. No, causally speaking, there is nothing there, except the neurobiology, which has a higher level feature of consciousness." [9]

The latter sentence however seems to express the reason why Searle holds to his conclusion. If indeed one presupposes that there is nothing else except the brain then somehow the brain has to cause consciousness. Similarly, if one presupposes metaphysical naturalism, then it is obvious that something natural has to function as an objective moral standard. But if one is open to other possibilities than metaphysical naturalism, such as those briefly stated in the discussion of P2 (Platonism, Divine Command Theory) then this particular reason to accept a naturalistic explanation of morality (namely that there is no alternative) is clearly false. Furthermore, it might be the case that non-naturalist theories can locate morality, for instance in the Platonic realm of Ideas or in the nature of a deity.

A possible reply to the location problem is that one can locate morality in certain collection of elementary particles, namely those collections of particles that form beings such that are capable of acting morally (such as human beings). It seems very intuitive to conclude that this is the case. However, this does not answer the question why, on naturalism, these collections of particles somehow 'have' morality and others do not. Furthermore, this reply also gives rise to the problem of speciesism.

\section{The Problem of Speciesism}

Connected to the location problem is the problem of speciesism. Speciesism means that one prefers one's own species to other species. In the case of morality it seems that ethicists separate human beings on one hand and other animals on the other. Human beings are moral agents but animals are not. But why would this be the case under naturalism? While contemplating an imaginary group of people living in a state of nature, Richard Taylor considers what they would think if one person would kill another person. "Such actions, though injurious to their victims, are 
no more unjust or immoral than they would be if done by one animal to another. A hawk that seizes a fish from the sea kills it, but does not murder it; and another hawk that seizes the fish from the talons of the first takes it, but does not steal it - for none of these things is forbidden. And exactly the same considerations apply to the people we are imagining." [10] Why would Taylor be wrong on naturalism? There has to be something special about human beings which can be connected to morality in such a way that human beings become moral agents and animals such as hawks do not. Obviously this is not a problem for those who would reject the difference between hawks and humans and would state that all animals exhibit moral behaviour (sometimes called pre-moral behaviour when it concerns animals with less evolved brains). This view however would leave us with a world filled with morally despicable creatures that eat each other, rape, steal and so forth. Most ethicist would shy away from that conclusion. There are philosophers and biologists who would argue that certain kinds of animals do exhibit moral behaviour. Usually this pertains to animals with higher cognitive functions, such as certain ape species [11].

Is this line of reasoning sufficient to show that there are natural facts concerning morality and these natural facts are somehow connected to the cognitive abilities of certain animals? It seems to me that once again this distinction is based upon the presupposition of metaphysical naturalism. For one could agree that only certain animals exhibit moral behaviour and are moral agents without having to hold that this is due to any natural reason. Suppose for instance that the reason some animals behave morally is due to the fact that these animals have consciousness. It appears that many ethicists who ascribe morality to animals also ascribe to them some kind of consciousness, albeit less advanced than human consciousness. But apart from epistemological issues involved with our knowledge of other minds, the issue once again becomes whether consciousness is reducible to the natural. And this has simply not been shown to be the case. Even worse, there are signs that the reductionist programme has failed. In the words of Thomas Nagel: "Consciousness is the most conspicuous obstacle to a comprehensive naturalism that relies only on the resources of physical science". [12] Therefore, on naturalism, there seems to be no reason for proposing that some animals act morally and others do not as long as there is no clear explanation of this difference in naturalistic terms.

\section{The Problem of Evolutionary Ethics}

This then brings me to the final problem with trying to connect the moral to the natural. The most promising venue for naturalist to take is to explain how morality evolved from species with virtually no moral systems to homo sapiens with its elaborate moral thoughts, codes and behaviours. According to evolutionary ethics morality is in place because it is a positive addition to the survival and reproduction of social animals [13], [14]. In essence, morality is a by-product of purely natural forces. This would solve both the location problem (morality is a natural property of those collections of elementary particles that are highly evolved animal species) and the speciesism problem (only those species with highly evolved social structures exhibit morality). One could therefore in theory construe a moral standard using these natural facts about evolution. Unfortunately, it seems that evolutionary ethics presents its own problem; instead of acting as an ontological foundation for morality it seems to function as the opposite: it eventually leads to nihilism.

The root of the problem lies with the shift that takes place in the meaning of moral terminology such as 'good' and 'bad'. The evolutionary ethicist seems to understand these words as meaning 'good for survival and reproduction' and 'bad for survival or reproduction'. But of course this is something different than the pre-Darwinian ethicist (let alone the common sense user) meaning of these terms. The philosopher of biology Michael Ruse puts it this way: "To be blunt, my Darwinian metaethics says that substantive morality is a kind of illusion, put in place by our genes, in order to make us good social co-operators." [15] In the end morality is "...just an aid to survival and reproduction and any deeper meaning is illusory." Ruse submits that "...properly understood, the Darwinian approach to ethics leads one to a kind of moral nonrealism." On moral progress he writes: "moral progress has to be likened to biological progress. Just like biological progress has no objective goal or goal whatsoever, also morality, a product of biological evolution, has no goal and therefore there is no objective progress. It points away from the possibility of our knowing objective morality.

Ruse is not the only one who would draw this conclusion. For instance, Simon Blackburn seems to make a similar claim when he states: "Nature has no concern for good or bad, right or wrong. . . . We cannot get behind ethics." [16] And Richard Dawkins notes that "The universe we observe has precisely the properties we should expect if there is, at bottom, no design, no purpose, no evil, no good, nothing but blind, pitiless indifference." [17] Sharon Street poses the following dilemma to the evolutionary ethicist who would claim that there are objective moral facts: "The challenge for realist theories of value is to explain the relation between these evolutionary influences on our evaluative attitudes, on the one hand, and the independent evaluative truths that realism posits, on the other. Realism, I argue, can give no satisfactory account of this relation." [18]

What are we to make of this conclusion drawn by a host of scholars on evolutionary ethics? Let me reformulate the problem by proposing the following dilemma. Either evolutionary ethics is the foundation of (what we usually mean by) morality or it isn't. If one tries to argue that evolutionary ethics is the foundation of morality, then one 
has the problem that in fact evolutionary ethics is about that which increases fitness (survival and reproduction) and this is not identical to what we usually refer to when we are discussing morality. In fact, many things that increase fitness are what we would usually describe as morally bad. Think for instance about those acts committed by the eugenics movements that were popular in the early $20^{\text {th }}$ century. Contemporary evolutionary ethicists would disagree strongly with the eugenics movement. They would explain that evolutionary ethics is about how morality evolved in our species, but that does not imply that we have to act accordingly. Thus it turns out that evolutionary ethics might explain the origin of morality, but even if it does it seems that it does not explain why we should act accordingly. This seems to be the reason why many scholars agree that given evolution it follows that morality is an illusion cooked up by natural selection to get us to survive and reproduce. But if we do not (have to) act according to our evolutionary moral instincts, then how should we act? This is exactly the dilemma: if evolutionary ethics is the foundation of morality then we should act to increase our fitness, which is almost universally rejected as being what morality is about, but if it isn't the foundation of morality then we still require a foundation for our current ethics. In both cases, evolutionary ethics fails as the foundation for morality. An example of this dilemma in action can be seen in Daniel Dennett's book Darwin's Dangerous Idea [19]. In the chapter concerning ethics he uses the following quote from Ruse and Wilson: "Morality, or more strictly our belief in morality, is merely an adaption put in place to further our reproductive ends." [20] Dennett's reply: "Nonsense. Our reproductive ends may have been the ends that kept us in the running till we could develop culture, and they may still play a powerful sometimes overpowering - role in our thinking, but that does not license any conclusion at all about our current values." I would suggest that Dennett is correct, but apparently he grounds our current morality in culture, which would lead to the conclusions that (1) morality is not grounded in nature and (2) morality is subjective.

The main question of this section was whether P3 is more likely to be true than false. I would submit that the location problem, the problem of speciesism and the problem of evolutionary ethics show that grounded morality in something natural is problematic at best. Therefore I would conclude that P3 is likely to be true.

\section{C1: If There Is Objective Moral Progress, Then a Non-natural Objective Moral Standard Exists}

The conclusion $\mathrm{C} 1$ follows necessarily from the truth of premises $\mathrm{P} 1, \mathrm{P} 2$ and $\mathrm{P} 3$. Two remarks are in order here. First, it is not my intention to prove that the premises are correct beyond reasonable doubt. This would be too high a standard. One simply has to show that the truth of the premise is more likely than its falsehood. The truth of the first two premises follows from the definitions as explained in the sections dealing with these premises. The third premise can be considered the weakest of the three discussed thus far. But it cannot be emphasized enough that a good proportion of biologists and philosophers dealing with evolutionary ethics would agree with P3: naturalist explanations of morality are either not objective, or simply about something else than what we usually consider to be morality. The evolutionary ethicist has given us no reason to believe that natural processes can account for any kind of objective morality, let alone an objective moral standard. It therefore seems plausible to conclude $\mathrm{C} 1$. Second, this conclusion by itself is worth mentioning for it clearly shows that one cannot be a moral objectivist without non-natural entities in ones ontology. The only way to accept the first three premises but to escape that which this conclusion entails is to deny the existence of objective moral progress in the first place. Obviously this is a route that some philosophers take: they would agree that morality is ultimately subjective. In the next section I will argue that this view is either incoherent with regards to moral progress, or otherwise unliveable.

\section{P4: There Is Objective Moral Progress}

I mentioned the abolishment of slavery, especially the trans-Atlantic slave trade, as an example of moral progress. But it seems to me that we have many more examples of cases that are viewed as moral progress. These cases include (but are not limited to) the abolishment of fossil fuels, other agreements to decrease climate change, the decrease of violence worldwide, the advent of animal rights, the acceptance of universal human rights and human equality, the abolishment of child conscription, etcetera. The question under discussion in this section is whether these are examples of objective moral progress. In one sense it would appear that many of these are instances of conventions; agreements between humans or groups of humans. But these agreements are far from arbitrary. The Universal Declaration of Human Rights for instance begins with the following words in its preamble: "Whereas recognition of the inherent dignity and of the equal and inalienable rights of all members of the human family is the foundation of freedom, justice and peace in the world..." The foundation of freedom, justice and peace in the world is not, according to the composers of this declaration, due to any kind of convention, but it is something that is inherent to human beings. Furthermore, the main normative ethical theories also presuppose morality to be objective. Whether one holds to utilitarianism, deontological ethics or virtue ethics; the roots of these three ethical theories are based upon some kind of objective principle. Therefore, one can account for the above list of 
apparent cases of moral progress by accepting that there is moral progress based on an objective standard.

Can the moral subjectivist similarly account for moral progress? There appear to be at least two problems for the moral subjectivist. The first is that, on subjectivism, the notion of moral progress seems incoherent. I explained under section P1 that moral progress means a change towards some kind of standard. For the objectivist this standard is mind-independent. But what kind of standard would suffice for the moral subjectivist? An examination of different subjectivist positions will show that the different kinds of subjectivist standards are incompatible with the notion of moral progress. An individual subjectivist (or individual relativist) believes that ones own opinions are the moral standard. But since people often disagree on what is moral, two individual subjectivists with opposing views will have the problem of both having to affirm their own ethical beliefs while also having to affirm that the other person has good reasons to affirm his/her own ethical beliefs. This consequence of individual subjectivism would make it impossible to talk about moral progress, since that notion would simply be a matter of personal taste. A cultural subjectivist (cultural relativist) would argue that morality is based on the history and practices of the culture that one lives in. But this view would also prevent moral progress. Since what is right is that which is currently morally acceptable within a culture, any type of change would be a move towards something that is different from the current culture. Therefore, a cultural subjectivist must hold that there is no such thing as moral progress, since any kind of change would be in contradiction to the culture that one has been brought up in.

Finally, it appears that those who claim to hold that moral facts are subjective (or even non-existent) have a difficult time in accepting the consequences of this view. Many proponents of subjectivism appear to be making statements that seem to be about objective moral facts. Take for instance Richard Dawkins, whom as quoted earlier concluded on the basis of evolutionary evidence that there is no good and no evil. But throughout his work, both oral and on paper, we can find propositions such as: "Do not indoctrinate your children. Teach them how to think for themselves, how to evaluate evidence, and how to disagree with you." [21] Dawkins does not seem to suggest that "indoctrination is wrong" relative to one's own subjective attitudes or those of one's culture, but indoctrination is wrong. How would such an idea fit in with moral subjectivism? Or take another quote from the same author about the Judeo-Christian God: "The God of the Old Testament is arguably the most unpleasant character in all fiction: jealous and proud of it; a petty, unjust, unforgiving control-freak; a vindictive, bloodthirsty ethnic cleanser; a misogynistic, homophobic, racist, infanticidal, genocidal, filicidal, pestilential, megalomaniacal, sadomasochistic, capriciously malevolent bully." Notice that Dawkins does not make this statement just to give his own personal opinion: he notes that this is the case, and apparently he has arguments for this position. I would submit that this attitude does not befit one who does not believe in the existence of good or evil. These are moral statements that appear to be objective, and the best explanation for them appearing to be objective is that they in fact are objective. Dawkins is not the only person who seems to be unable to act according to his own ethics: it seems to be difficult to live a life devoid of seemingly objective moral statements. Similarly, when making statements about moral progress, such as "the abolishment of slavery was good", it is theoretically unusable for moral subjectivists. What they would have to say would be closer to "It is my personal opinion/cultural opinion/evolutionary sentiment that the abolishment of slavery was good". Obviously it is quite possible to utter such sentences. But in practice not many of those concerned with moral progress use this kind of language. Mostly objective language is used and this is another reason to think that $\mathrm{P} 4$ is more likely to be true than false.

\section{C2: A Non-natural Objective Moral Standard Exists}

If the premises $\mathrm{P} 1$ to $\mathrm{P} 4$ are true then $\mathrm{C} 2$ follows necessarily from these premises. This conclusion would entail that non-natural things exist (namely a non-natural objective moral standard) and therefore metaphysical naturalism would be false. If this is the case then the ethical community would benefit greatly from philosophical research pertaining to the question what kind of non-natural entity or entities could serve as the foundation for objective morality. I have given a few examples of possible non-natural ontological entities that could serve this purpose, such as Platonic Ideas or a non-natural deity. It seems to me that such entities do a much better job at providing the basis for moral progress then any natural theory. It seems that many of our current ethical beliefs are also based on this conclusion. Take the preamble of the Declaration of Independence. It states that "We hold these truths to be self-evident, that all men are created equal, that they are endowed by their Creator with certain unalienable Rights that among these are Life, Liberty and the pursuit of Happiness." It grounds human rights in the existence of a Creator. Although I do not want to conclude here that one necessarily requires such a deity to ground morality, it seems that this view does hold the benefit that it allows for the existence of objective moral facts, such as those rights found in the Declaration of Independence. Although belief in Platonic Ideas and non-natural deities is becoming less common among professional philosophers, it appears that the naturalist still has a lot of work to do to show that their ontology is robust enough to ground and explain morality in general, and moral progress in particular.

In this paper I have assumed that moral realism is true 
and have shown that on this view moral progress requires a non-natural objective moral standard. As I have mentioned in the introduction, one could reject this assumption and hold to some form of moral anti-realism which would be non-objective but subjective. I have already shown that a moral subjectivist would have to reject the notion of moral progress in its entirety, which would be a disturbing consequence since we want to affirm that moral progress has been made throughout history, such as in the case of slavery. But there are other reasons to reject moral anti-realism as well. I will briefly mention two such arguments, one philosophical argument and one psychological argument. The British ethicist A.C. Ewing argues that if morality is subjective, then one cannot argue in favour or against any moral position [22]. Moral statements would be similar to statements about taste. Just like one cannot properly argue that "vanilla is tasty" since that statement represent a subjective opinion, so too moral statements, if subjective, would be indefensible. The psychological argument consists of recent studies suggesting that meta-ethical attitudes affect moral behaviour. In one study participants primed with a realist (objectivist) ethical view were more likely to donate to charity than those who were primed with anti-realist (subjectivist) views [23]. Similarly, those who are primed with the meta-ethical view of moral subjectivism were likelier to cheat than those primed with moral realism [24]. Thus there are reasons to hold that being a moral subjectivist negatively affects behaviour. In conclusion: there are good reasons for accepting moral realism, as a majority of professional philosophers do. If one accepts moral realism then this paper has argued that moral progress requires a non-natural objective moral standard.

\section{REFERENCES}

[1] Bourget D, Chalmers D (2013) What Philosophers Believe. PhilPapers. http://philpapers.org/archive/BOUWDP. Accessed 28 September 2015.

[2] Mackie J (1977) Ethics: inventing right and wrong. Penguin books, London.

[3] Jamieson D (2002) Is there progress in morality? Utilitas $14: 318-338$

[4] Moore G (1903) Principia ethica. Cambridge University Press.
[5] Copp D (2007) Morality in a natural world: selected essays in metaethics, Cambridge University Press.

[6] Moore, G.E (1903) Principia Ethica. Cambridge University Press.

[7] Miller, A (2013) Contemporary metaethics: an introduction. Polity Press, Cambridge.

[8] Jackson F (1998) From metaphysics to ethics: a defense of conceptual analysis. Oxford University Press.

[9] Searle J (2012) Why I am not a property dualist. Journal of Consciousness Studies 9:57-64

[10] Taylor R (1985) Ethics, faith and reason. Prentice Hall, Englewood Cliffs, NJ.

[11] De Waal F (2006) Primates and philosophers. Princeton University Press.

[12] Nagel T (2012) Mind and cosmos. Oxford University Press.

[13] Harris S (2011) The moral landscape. Free Press, New York.

[14] Joyce, R (2005) The evolution of morality. MIT Press.

[15] Ruse M (2011) Evolution and ethics. In: Gordon B, Dembski W (eds) The nature of nature. Intercollegiate Studies Institute Books, Wilmington DE.

[16] Blackburn S (2002) Being good: a short introduction in ethics. Oxford University Press.

[17] Dawkins R (1995) River out of Eden. Basic Books/Harper Collins, New York.

[18] Street S (2006) A Darwinian dilemma for realist theories of value. Philosophical Studies 127:109-166.

[19] Dennett D (1995) Darwin's Dangerous Idea. Penguin books, London.

[20] Ruse M and Wilson E (1985) The evolution of ethics. New Scientist 17:50-52.

[21] Dawkins R (2006) The God delusion. Bantam books, New York.

[22] Ewing, A C (1944) 'Subjectivism and Naturalism in Ethics', Mind Vol. 53, No. 210, pp. 120-141.

[23] Young, L, \& Durwin, A J (2012). Moral realism as moral motivation: The impact of meta-ethics on everyday decision-making. Journal of Experimental Social Psychology, Volume 49, 302-306.

[24] Rai, T S, Holyoak, K J (2013) Exposure to moral relativism compromises moral behavior, Journal of Experimental Social Psychology. Volume 49, Issue 6, November 2013, Pages 995-1001. 